\title{
trans-4-Acryloyloxyazobenzene/Vinylidene Chloride Copolymers. Nuclear Magnetic Resonance Characterization
}

\author{
Ajaib Singh Brar ${ }^{\dagger}$ and Muthiah ThIYAgarajan \\ Department of Chemistry, Indian Institute of Technology, \\ New Delhi-110 016, India
}

(Received April 12, 1999)

\begin{abstract}
Acryloyloxyazobenzene/vinylidene chloride (A/V) copolymers of different monomer concentrations were prepared by solution polymerization using benzoyl peroxide as initiator. The copolymer composition was determined from the quantitative ${ }^{13} \mathrm{C}\left\{{ }^{1} \mathrm{H}\right\}$ NMR spectrum. The carbonyl carbon of A- and the quaternary carbon of V-centered resonances were used for determining the sequences in terms of the distribution of A- and V-centered triads. The sequence distribution of A- and V-centered triads determined from ${ }^{13} \mathrm{C}\left\{{ }^{1} \mathrm{H}\right\}$ NMR spectrum of the copolymer is in good agreement with triad concentration calculated from statistical model. The comonomer reactivity ratios, determined by both Kelen-Tüdos (KT) and nonlinear error in variables (EVM) method are $r_{\mathrm{A}}=0.36 \pm 0.03, r_{\mathrm{V}}=1.02 \pm 0.06 ; r_{\mathrm{A}}=0.37$ and $r_{\mathrm{V}}=1.04$, respectively. ${ }^{13} \mathrm{C}$ Distortionless enhancement by polarization transfer (DEPT) spectrum was used to differentiate the resonance signals of methine (A) and methylene carbon signals of A- and V-units. Assignments to the methine and methylene resonance signals have been assigned up to the tetrad levels using 2D HSQC experiments. The geminal coupling in the methylene and methine proton region is shown in the 2D TOCSY spectrum.
\end{abstract}

KEY WORDS trans-4-Acryloyloxyazobenzene/Vinylidene Chloride Copolymer / Microstructure / Nuclear Magnetic Resonance Spectroscopy /

Photoresponsive polymers are used in constructing photoactive devices in several fields such as printing, photolithography and photosensors. ${ }^{1}$ It is well known that NMR spectroscopy is probably the most effective method for characterizing the configurational structure of polymers because the chemical shift is sensitive to configurational sequences. ${ }^{2,3}$ Two dimensional NMR experiments $^{4,5}$ have been used as the most reliable method for determining the conformational ${ }^{6,7}$ and configurational $^{8}$ microstructure of the copolymers. Suzchen et al. ${ }^{9}$ studied photoinduced doping characteristics such as doping position and type of charge carriers by doping polyaniline with vinylidene chloride/methylacrylate copolymer. Hangguan et al. ${ }^{10}$ studied the effects of the various constituents on the mechanical properties of the polymer composites based on vinylidene chloride/ methylmethacrylate copolymer cross-linked with vinylterminated poly(caprolactone). Menge et al. ${ }^{11}$ investigated microdynamics and ${ }^{13} \mathrm{C}$ relaxation measurements on vinyl chloride/vinylidene chloride copolymer in solution by NMR spectroscopy. Lee et al. ${ }^{12}$ have reported the physical and mechanical properties of vinylidene chloride/butylmethacrylate copolymer. Solaro et al. have reported ${ }^{13} \mathrm{C}\left\{{ }^{1} \mathrm{H}\right\}$ NMR studies on Poly(trans-4-methacryloyloxyazobenzene) ${ }^{13}$ and trans-4methacryloyloxyazobenzene/menthyl methacrylate copolymer. ${ }^{14}$ The chiroptical properties and photochromic behavior of the copolymers were reported by Altomare et al. ${ }^{15}$

To the best of our knowledge, the detailed microstructure study of trans-4-acryloyloxyazobenzene/vinylidene chloride $(\mathrm{A} / \mathrm{V})$ copolymers have not been reported so far. In this work, we report the stereochemical structure and sequence distribution of $(\mathrm{A} / \mathrm{V})$ copolymers by one and two-dimensional NMR spectroscopy. The ${ }^{1} \mathrm{H}$ NMR spectrum of copolymer is complex and has

$\dagger$ To whom all correspondence should be addressed. been interpreted with the help of 2D heteronuclear single quantum correlation (HSQC) NMR spectroscopy. The reactivity ratios of the comonomers have been calculated using Kelen-Tüdos $(\mathrm{KT})^{16}$ and the non-linear Error in Variable Model (EVM) ${ }^{17}$ methods, using the compositional data. The A- and V-centered triad sequence distribution obtained from ${ }^{13} \mathrm{C}\left\{{ }^{1} \mathrm{H}\right\}$ NMR spectrum and are compared with those calculated from the first order Markov model using reactivity ratios determined from the $\mathrm{EVM}^{18}$ method.

\section{EXPERIMENTAL}

The details of the copolymerization process and NMR measurements are explained in our earlier publications. $^{19,20}$

\section{RESULTS AND DISCUSSION}

\section{Reactivity Ratios Determination}

The copolymer composition of the A/V copolymers were determined from the quantitative ${ }^{13} \mathrm{C}\left\{{ }^{1} \mathrm{H}\right\}$ NMR spectra using the inverse gated decoupling pulse program with $8 \mathrm{~s}$ as delay time. Table I shows the comonomers mole fractions in the feed and in the copolymer. The initial estimate of the reactivity ratios was done by the KT method. The values of the terminal model reactivity ratios obtained from the KT plot are $r_{\mathrm{A}}=0.36 \pm 0.03$ and $r_{\mathrm{V}}=1.02 \pm 0.06$. These values along with the copolymer data were used to calculate the reactivity ratios using the non-linear EVM method. The values of the reactivity ratios obtained from EVM are $r_{\mathrm{A}}=0.37$ and $r_{\mathrm{V}}=1.04$. The copolymer composition obtained from the copolymer equation using the terminal model reactivity ratios $\left(r_{\mathrm{A}}=0.37\right.$ and $\left.r_{\mathrm{V}}=1.04\right)$ are compared with those found experimentally, are shown in Figure 1. The experimental points are in good agreement with the theoretically calculated, indicating that the reactivity ratios obtained 
Table I. Copolymer composition data and molecular weight of the trans-4-acryloyloxy azobenzene/vinylidene chloride copolymers by GPC measurements

\begin{tabular}{|c|c|c|c|c|c|c|c|}
\hline \multirow{2}{*}{ Sample } & \multirow{2}{*}{$f_{\mathrm{A}}$} & \multirow{2}{*}{$f_{\mathbf{V}}$} & \multirow{2}{*}{$F_{\mathrm{A}}$} & \multirow{2}{*}{$F_{\mathrm{v}}$} & \multirow{2}{*}{$\frac{\bar{M}_{w}\left(\times 10^{-4}\right)}{\mathrm{g} \mathrm{mol}^{-1}}$} & \multirow{2}{*}{$\frac{\bar{M}_{n}\left(\times 10^{-4}\right)}{\mathrm{g} \mathrm{mol}^{-1}}$} & \multirow{2}{*}{ Polydispersity } \\
\hline & & & & & & & \\
\hline AV3 & 0.3 & 0.7 & 0.25 & 0.75 & 1.7 & 1.4 & 1.2 \\
\hline AV4 & 0.4 & 0.6 & 0.33 & 0.67 & 3.4 & 2.1 & 1.6 \\
\hline AV5 & 0.5 & 0.5 & 0.41 & 0.59 & 3.9 & 2.6 & 1.5 \\
\hline AV6 & 0.6 & 0.4 & 0.48 & 0.52 & 4.3 & 2.7 & 1.6 \\
\hline AV7 & 0.7 & 0.3 & 0.56 & 0.44 & 4.9 & 3.1 & 1.6 \\
\hline AV8 & 0.8 & 0.2 & 0.66 & 0.34 & 5.2 & 2.8 & 1.9 \\
\hline
\end{tabular}

$f_{\mathrm{A}}$ and $f_{\mathrm{V}}$ are the mole fractions of A- and $\mathrm{V}$-comonomers, respectively in feed. $F_{\mathrm{A}}$ and $F_{\mathrm{V}}$ are the mole fractions of $\mathrm{A}$ - and $\mathrm{V}$-comonomers, respectively in the copolymer. $\bar{M}_{w}$ and $\bar{M}_{n}$ are the weight and number average molecular weights of the copolymer, respectively.

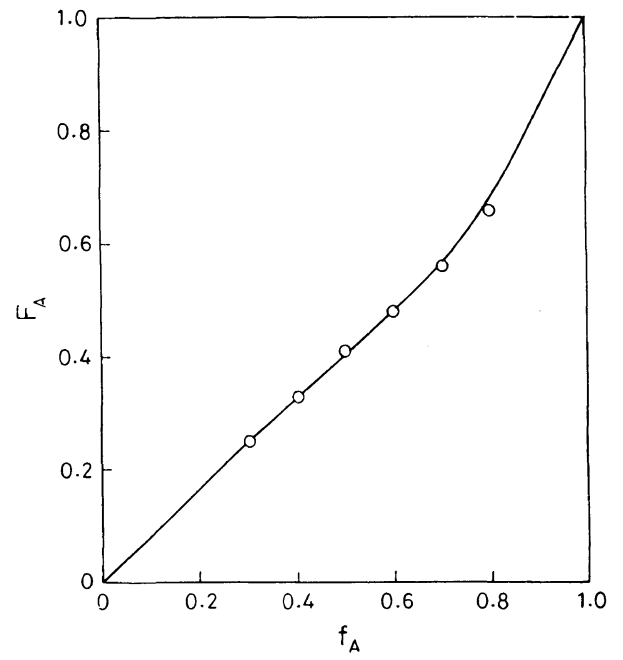

Figure 1. Theoretical composition curve along with experimentally determined copolymer composition $(\mathrm{O})$.

from the compositional data are reliable. The number average $\left(\bar{M}_{n}\right)$ and weight average $\left(\bar{M}_{w}\right)$ molecular weights and polydispersity of the $\mathrm{A} / \mathrm{V}$ copolymers are given in Table I.

\section{${ }^{13} \mathrm{C}$ AND ${ }^{1} \mathrm{H}$ NMR STUDIES}

The ${ }^{13} \mathrm{C}\left\{{ }^{1} \mathrm{H}\right\}$ NMR spectrum of the A/V copolymer $\left(F_{\mathrm{A}}=0.48\right)$ is shown in Figure 2 along with the signal assignments. The assignments of aromatic carbon resonance of $\mathrm{M}$-monomeric unit have been reported in earlier publications. ${ }^{19,20}$ The extent of the overlap of various methylene and methine carbon signals cannot be ascertained from the ${ }^{13} \mathrm{C}\left\{{ }^{1} \mathrm{H}\right\}$ NMR spectra alone. These overlapping regions can be resolved by employing DEPT-135 and 2D HSQC experiments. Figure 3 shows the DEPT-135 spectra for different composition of the A/V copolymers, in which the methine carbon resonances are positive and the methylene carbon resonances of $\mathrm{A}$ - and $\mathrm{V}$-units are negative phase. The methine and methylene carbon resonances showed multiplets, indicating that they are sensitive towards the compositional and configurational sequences and can be used for the determination of the copolymerization mechanism. The methine carbon resonances show three clear regions. On comparison with the NMR spectra of poly(trans-4acryloyloxyazobenzene) (PAB) and change in intensity with the change in copolymer composition, the methine carbon signal at $\delta 41.8,41.3$, and $40.67 \mathrm{ppm}$ are assigned to AAA, AAV, and VAV triads, respectively. The cross peaks at $\delta 41.8 / 3.19,41.3 / 3.58$, and $40.6 / 3.95 \mathrm{ppm}$ are assigned to AAA, AAV, and VAV triads, respectively (Figures $4 a$ and $4 b$ ).

The signals of methylene carbon are assigned to three dyad regions, AA $(\delta 34.6-39.5 \mathrm{ppm})$, VA (AV) $(\delta$ $49.0-53.5 \mathrm{ppm})$ and VV $(\delta 61.5-64.5 \mathrm{ppm})$ (Figure 3$)$. The intensities of the lines within each dyad vary with the copolymer composition and thus can be assigned up to tetrad sequences. The central methylene proton of AA centered tetrads show cross peak (Figure $4 \mathrm{~b}$ ) at $\delta$ $36.0 / 2.27,36.6 / 2.65$, and $37.75 / 2.4 \mathrm{ppm}$ are assigned to AAAA, AAAV, and VAAV tetrads, respectively. The resonance signals at $\delta 51.0,51.5$, and $52.0 \mathrm{ppm}$ are assigned to AAVA, AAVV, and VAVV tetrads (Figure 3) respectively on the basis of change in the intensity with the change in copolymer composition. The central methylene protons of the AV centered tetrads, are non equivalent and show two cross peaks in the proton axis (Figure 4b) at $\delta 51.0 / 2.55(\delta 51.0 / 3.22), \quad \delta 51.5 / 2.86$ $(\delta 51.5 / 3.3), \delta 52.0 / 2.66(\delta 52.0 / 3.10) \mathrm{ppm}$ are assigned to AAmVA, AAmVV (VAmVA) and VAmVV meso tetrad sequences, respectively. The three signals in the $\mathrm{VV}$ dyad region are assigned to VVVV $(\delta 62.6 \mathrm{ppm})$, VVVA ( $\delta 63.5 \mathrm{ppm})$ and AVVA ( $\delta 64.0 \mathrm{ppm})$ tetrad sequences. Thus the cross peaks at $\delta 62.6 / 3.84,63.5 / 3.75$, and $64.0 / 3.65 \mathrm{ppm}$ are assigned to VVVV, VVVA, and AVVA tetrads, respectively (Figure $4 b$ ).

The ${ }^{1} \mathrm{H}$ NMR spectrum of $\mathrm{A} / \mathrm{V}$ copolymer is broad and overlapping, whose assignments are done with the help of 2D HSQC experiments and shown in Figures 5a and $5 \mathrm{~b}$. At shorter mixing time, the direct coupling between the bonded protons can be observed. Whereas at higher mixing time, the long-range relay coupling through magnetization transfer can be seen. In this copolymer system due to the presence of quaternary carbon in vinylidene chloride the long-range relay coupling was not observed in 2D TOCSY spectrum at a mixing time of $80 \mathrm{~ms}$. Figure 6 shows 2D TOCSY spectrum of $\mathrm{A} / \mathrm{V}$ copolymer at a mixing time of $4 \mathrm{~ms}$. The AAmVA $(\delta 3.22 / 2.55 \mathrm{ppm})$, AAmVV (VAmVA) $(\delta 3.3 / 2.86 \mathrm{ppm})$, and VAmVV $(\delta 3.10 / 2.66 \mathrm{ppm})$ meso tetrads of methylene carbon resonance signals, which are seen in 2D HSQC spectrum, are confirmed by 2D TOCSY spectrum at a mixing time of $4 \mathrm{~ms}$ and are labelled as $\mathrm{A}$, $\mathrm{B}$, and $\mathrm{C}$, respectively. In the AAAV tetrad the central methylene protons show coupling with methylene 


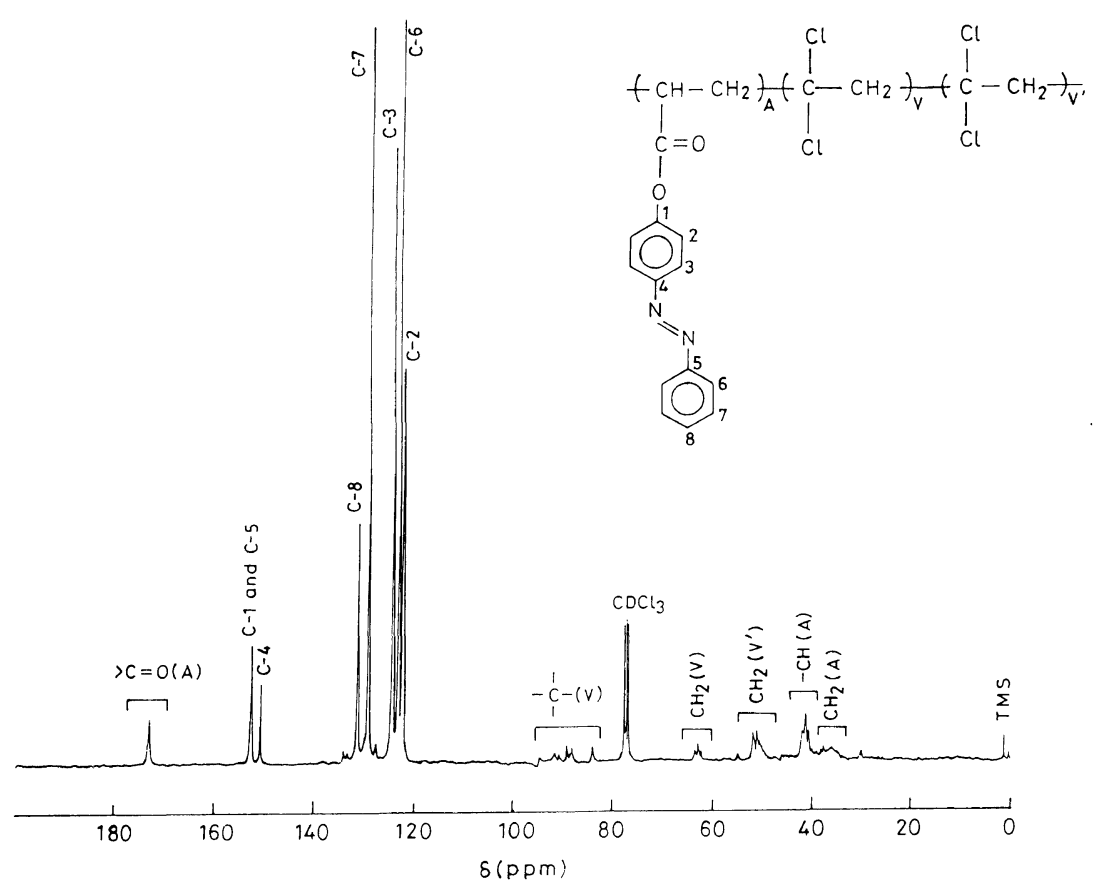

Figure 2. $75.5 \mathrm{MHz}^{13} \mathrm{C}\left\{{ }^{1} \mathrm{H}\right\} \mathrm{NMR}$ spectrum of the trans-4-acryloyloxyazobenzene/vinylidene chloride copolymer $\left(F_{\mathrm{A}}=0.48\right)$ in $\mathrm{CDCl}_{3}$.

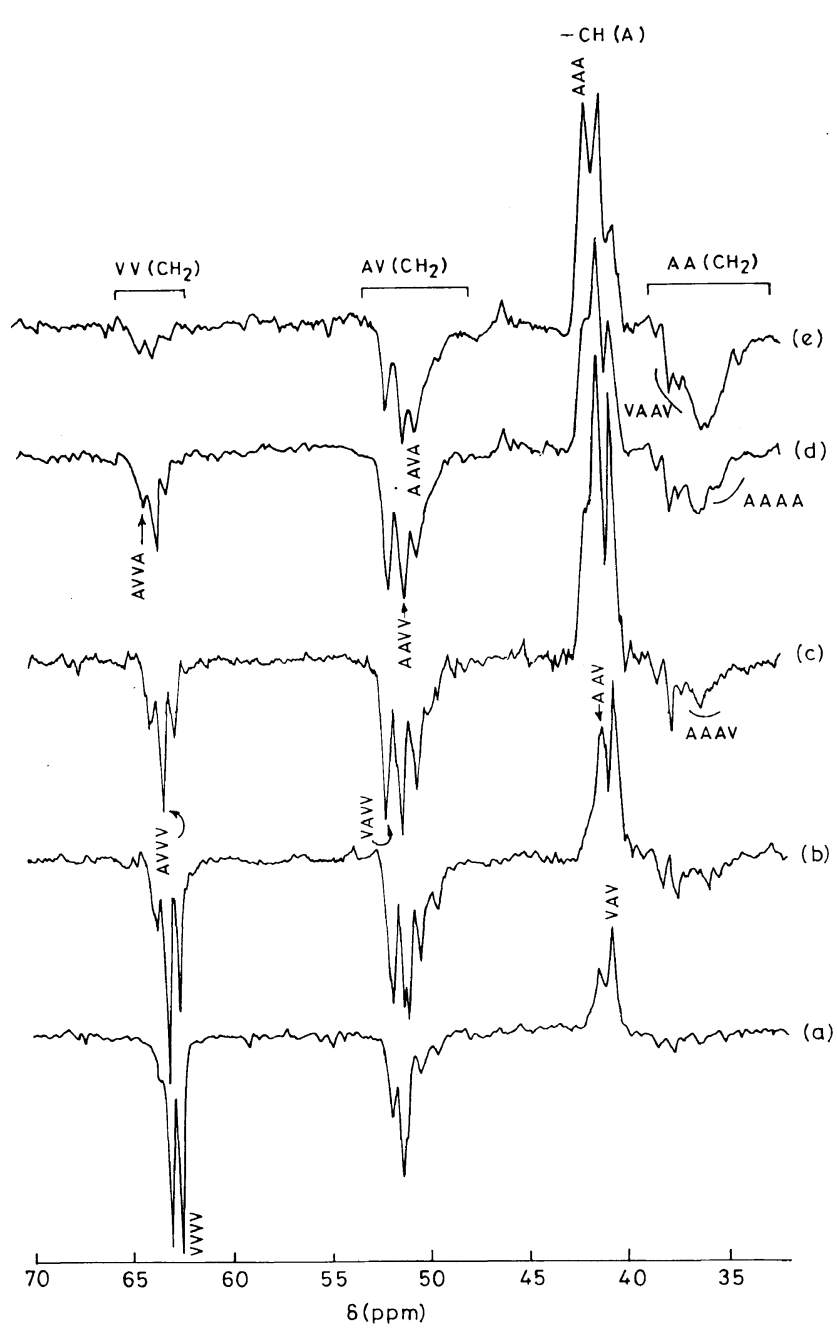

Figure 3. The DEPT-135 spectra showing the methine and methylene carbon resonance signals of $\mathrm{A}$ - and $\mathrm{V}$-units in different copolymer compositions $\left(F_{\mathrm{A}}\right)($ a) 0.25 , (b) 0.33 , (c) 0.41 (d) 0.48 , and (e) 0.66 in $\mathrm{CDCl}_{3}$. protons at $\delta 2.56 / 1.98,2.58 / 2.13$, and $2.59 / 2.05 \mathrm{ppm}$ are assigned to AArArV (1), AAmArV (AArAmV) (2), and AAmAmV (3) tetrad sequences, respectively.

The $\mathrm{CH}$ protons in AAA, AAV, and VAV triads are configurational sensitive. In the AAA triad, the central methine protons at $\delta 2.93,3.08,3.13$, and $3.19 \mathrm{ppm}$ show three bond coupling with the methylene protons at $\delta 2.45,2.33,2.21$, and $2.47 \mathrm{ppm}$. These coupling cross peaks are assigned to $\operatorname{ArArA}(4), \operatorname{AmArA}(5), \operatorname{ArAmA}$ (6), and AmAmA (7) triad sequences, respectively. In the AAV triad, the central methine protons at $\delta 3.41,3.52$, and $3.55 \mathrm{ppm}$ show three bond coupling with the methylene protons at $\delta 2.72,2.33$, and $2.17 \mathrm{ppm}$. These coupling cross peaks are assigned to ArAV (8), VArAV (10), and VAmAA (11) sequences, respectively. The central methine proton $(\delta 3.49 \mathrm{ppm})$ of the AAV triad shows three bond coupling with the two non equivalent methylene protons at $\delta 3.19$ and $2.57 \mathrm{ppm}$, is assigned to AmAV (9) triad sequence, thus the cross peak at $\delta 3.49 / 2.57$ (3.49/3.19) ppm is due to the geminal coupling of the non equivalent methylene protons. The central methine proton of VAV shows a coupling with methylene proton of VAVV and VAVA (AAVV). Thus the cross peaks at $\delta 3.89 / 3.06$ and $3.93 / 3.29 \mathrm{ppm}$ are assigned to VAAVV (12) and VAAVA (13) pentad sequences, respectively.

The signals in the region of $\delta 172.25-174.0$ and $\delta 83.0-93.5 \mathrm{ppm}$ are assigned to carbonyl and quaternary carbon resonances of A- and V-monomeric units showed multiplets, indicating that they are sensitive towards the compositional sequences and can be used for the assessment of the copolymerization mechanism. The expanded ${ }^{13} \mathrm{C}\left\{{ }^{1} \mathrm{H}\right\}$ NMR spectra of the carbonyl and quaternary carbon resonances of $\mathrm{A}$ - and $\mathrm{V}$-units in the $\mathrm{A} / \mathrm{V}$ copolymers are shown in Figures $7 \mathrm{a}$ and $7 \mathrm{~b}$. The signals in the region of $\delta 172.25-174.0 \mathrm{ppm}$ are assigned to carbonyl carbon resonance of A- unit Figure 7 a. The signals around $\delta 172.25-172.8,172.8-173.4$, 


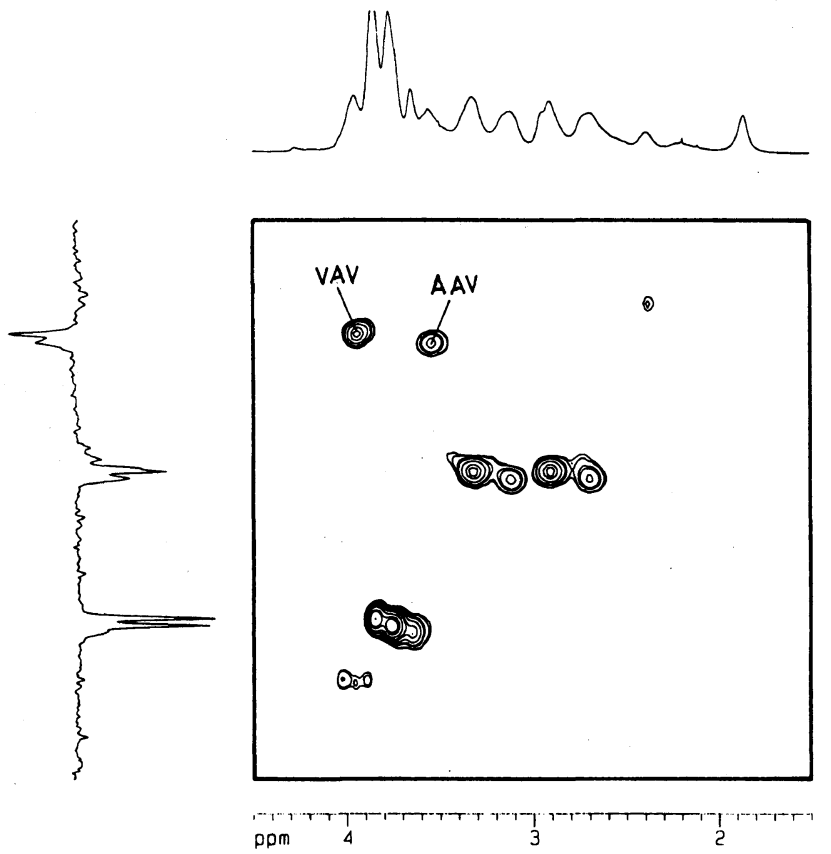

(a)

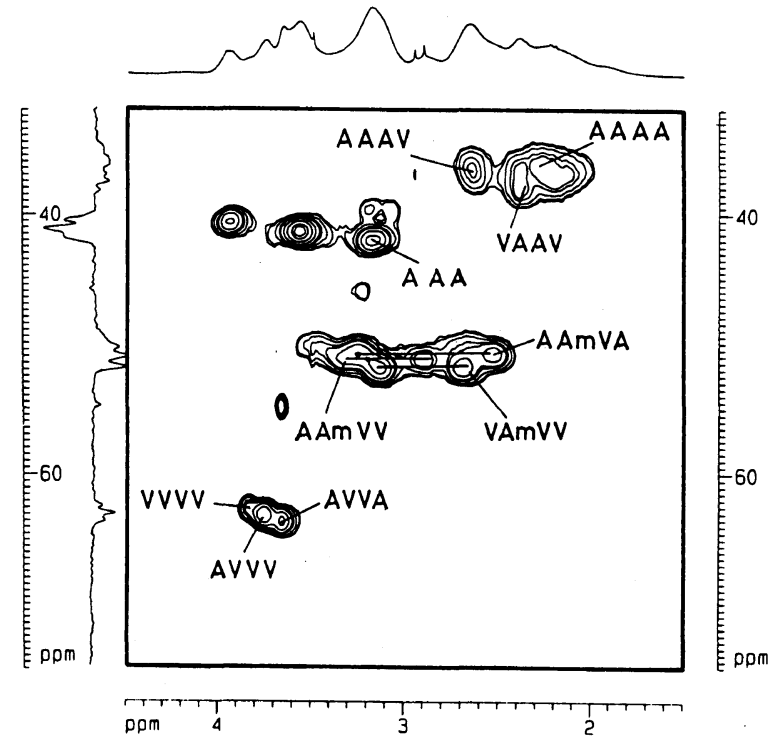

(b)

Figure 4. $75 \mathrm{MHz} 2 \mathrm{D}-\mathrm{HSQC}$ NMR spectrum of the $\mathrm{A} / \mathrm{V}$ copolymer (a) $F_{\mathrm{A}}=0.25$ and (b) $F_{\mathrm{A}}=0.48$ in $\mathrm{CDCl}_{3} .\left({ }^{1} \mathrm{H}-\mathrm{x}\right.$ axis and ${ }^{13} \mathrm{C}-\mathrm{y}$ axis.)
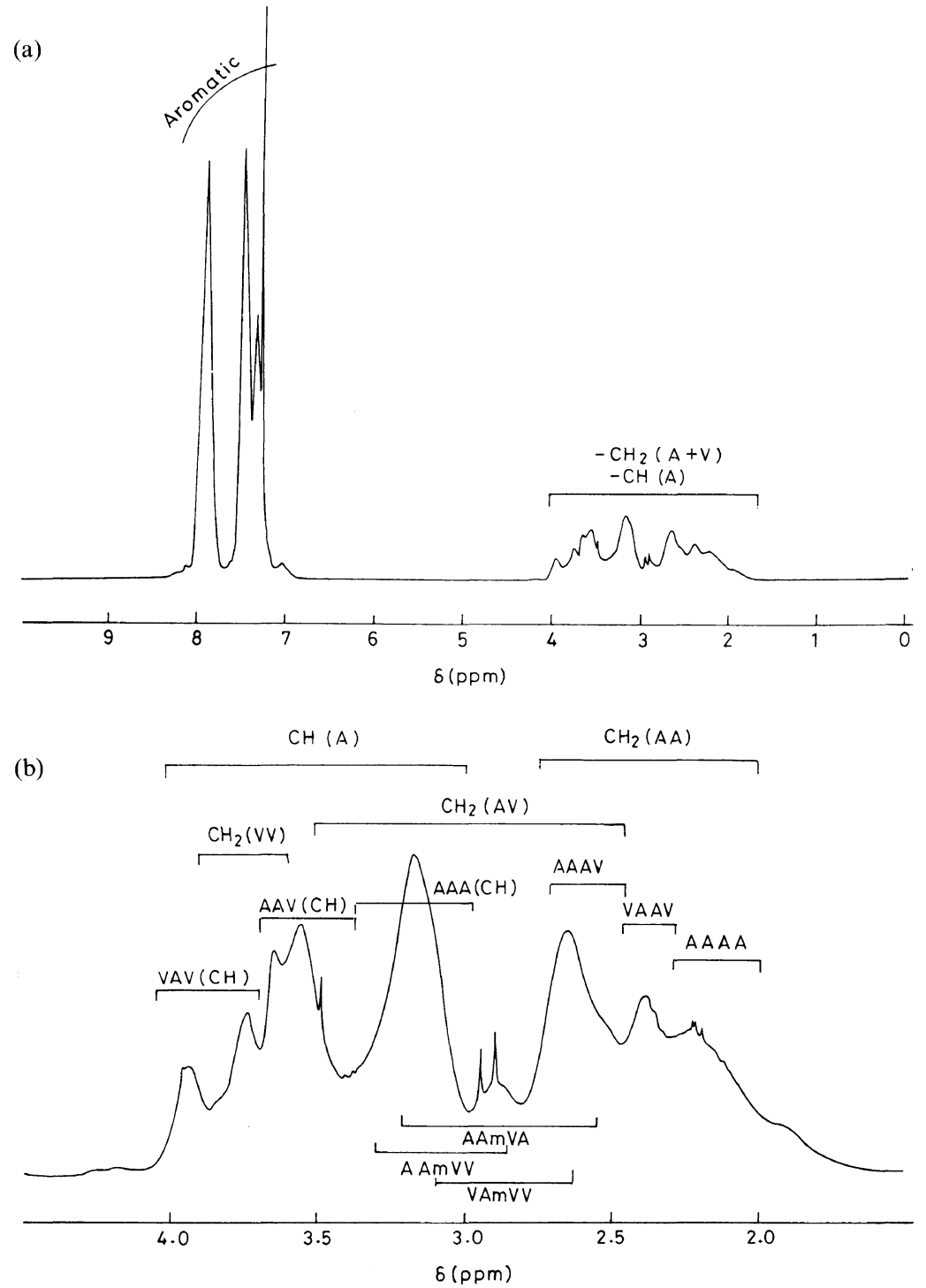

Figure 5. (a) $300 \mathrm{MHz}{ }^{1} \mathrm{H}$ NMR spectrum of $\mathrm{A} / \mathrm{V}$ copolymer $\left(F_{\mathrm{A}}=0.48\right)$ in $\mathrm{CDCl}_{3}$, (b) Expanded aliphatic carbon resonance signals. 


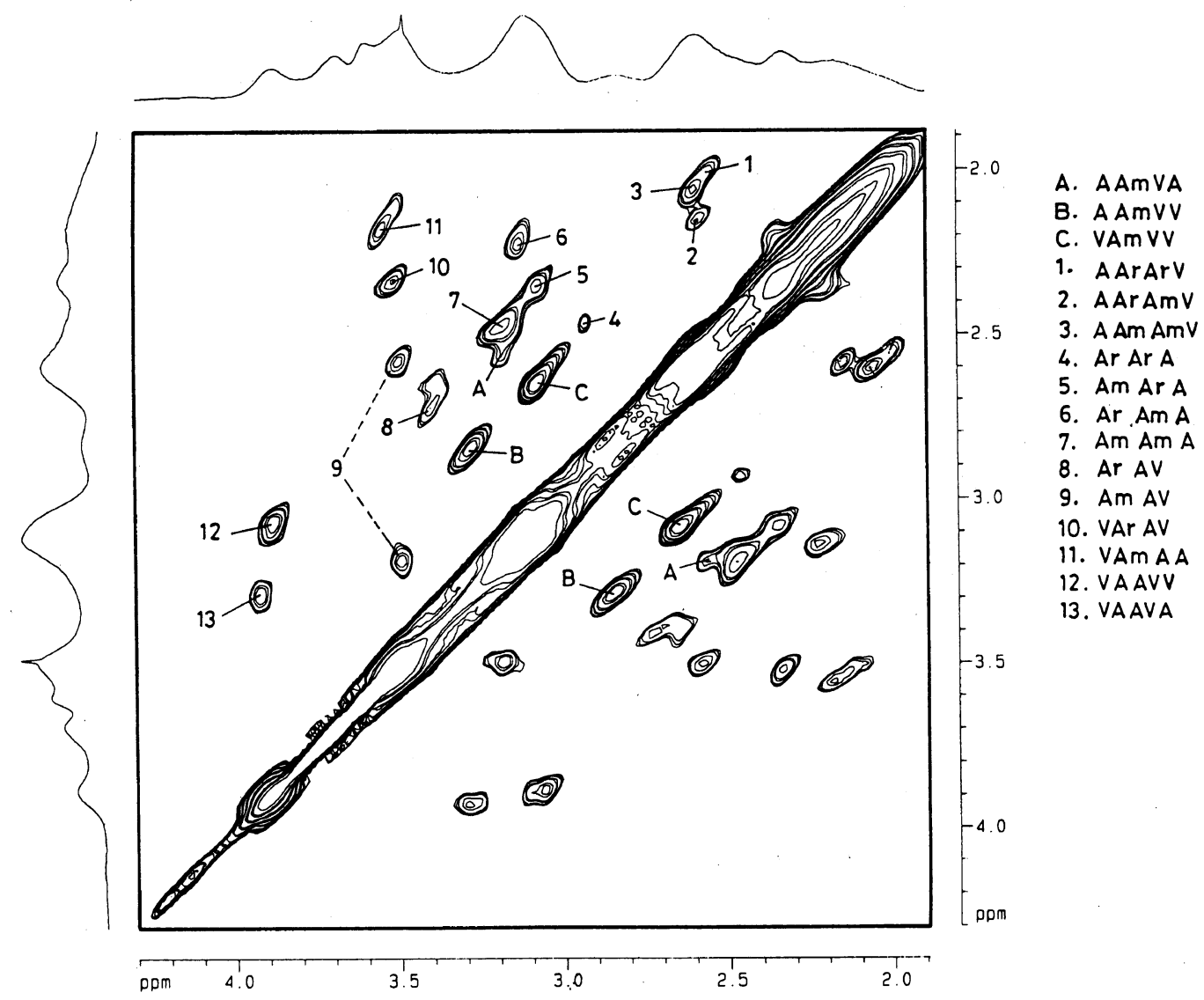

Figure 6. The homonuclear $2 \mathrm{D}$ TOCSY spectrum of $\mathrm{A} / \mathrm{V}$ copolymer $\left(F_{\mathrm{A}}=0.48\right)$ at a mixing time of $4 \mathrm{~ms}$ in $\mathrm{CDCl}_{3}$.
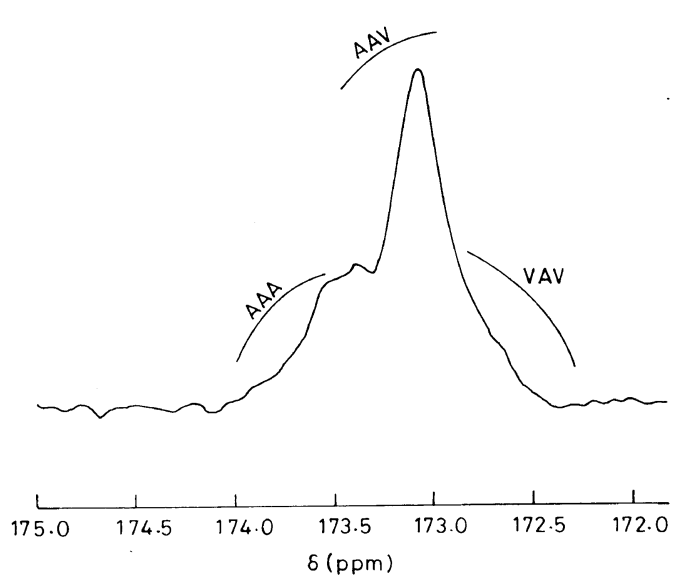

(a)
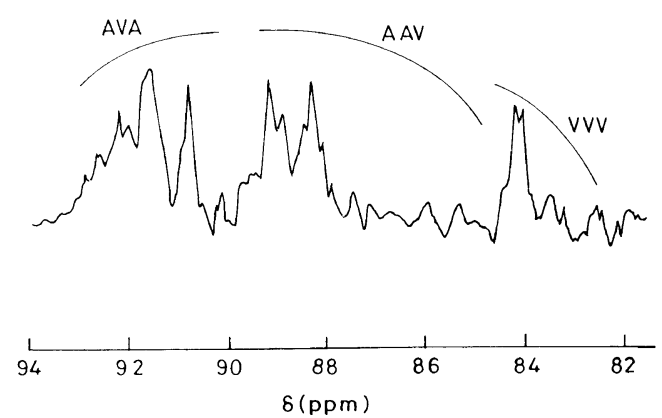

(b)

Figure 7. (a) Expanded carbonyl carbon resonance signals of the A-monomeric unit $\left(F_{\mathrm{A}}=0.48\right)$. (b) Expanded quaternary carbon resonance signals of the $\mathrm{V}$-monomeric unit in the $\mathrm{A} / \mathrm{V}$ copolymer $\left(F_{\mathrm{A}}=0.48\right)$ in $\mathrm{CDCl}_{3}$. and $173.4-174.0 \mathrm{ppm}$ were assigned to VAV, AAV, and AAA triads, respectively on the basis of the variation in the resonance signals with the copolymer composition.

The signals in the region of $\delta 82.2-93.5 \mathrm{ppm}$ are assigned to quaternary carbon resonances of $\mathrm{V}$-units Figure $7 \mathrm{~b}$. The signals around $\delta 82.2-85.5, \delta 85.5-90.0$, and $\delta 90.0-93.0 \mathrm{ppm}$ are assigned to $\mathrm{VVV}, \mathrm{AVV}$, and AVA triads, respectively on the basis of the variation in the copolymer composition. The concentration of various A- and V-centered triads were calculated from the relative areas of the resonance signals. Assuming the Alfrey-Mayo (first order Markov terminal model) to be valid at any moment for these low conversion copolymers. The triad fractions can be calculated using the terminal model reactivity ratios $r_{\mathrm{A}}=0.37$ and $r_{\mathrm{V}}=1.04$. Table II shows the A- and V-centered triad fractions calculated from Alfrey-Mayo model, using the Harwood's program and experimentally determined triad fractions. There is a good agreement between the calculated and the experimentally (NMR) determined triad fractions.

\section{Monte Carlo Simulation Studies}

Monte Carlo simulation, another potential tool for microstructure determination is used to monitor the changes in copolymer sequence behavior during the course of the polymerization. The triad fraction values estimated by MC simulation method were compared with the triad fraction values obtained from experimental NMR method and theoretical models. A good agreement between these values is evident from Table II. The correlation coefficient for simulated data (MC) with the 
Table II. Triad fractions calculated from NMR spectra and Harwood's terminal model in A/V copolymers

\begin{tabular}{|c|c|c|c|c|c|c|c|c|c|c|c|}
\hline \multirow{2}{*}{$\begin{array}{c}\text { Sample } \\
\text { No. }\end{array}$} & \multirow[b]{2}{*}{$F_{\mathrm{A}}$} & \multirow[b]{2}{*}{ Triads } & \multicolumn{3}{|c|}{ Triad fractions $^{\mathrm{a}}$} & \multirow{2}{*}{$\begin{array}{c}\text { Sample } \\
\text { No. }\end{array}$} & \multirow[b]{2}{*}{$F_{\mathrm{A}}$} & \multirow[b]{2}{*}{ Triads } & \multicolumn{3}{|c|}{ Triad fractions $^{\mathbf{a}}$} \\
\hline & & & ${ }^{13} \mathrm{C}\left\{{ }^{1} \mathrm{H}\right\}$ NMR & $\begin{array}{c}\text { Alfrey- } \\
\text { Mayo }\end{array}$ & $\begin{array}{c}\text { Monte } \\
\text { Carlo }\end{array}$ & & & & ${ }^{13} \mathrm{C}\left\{{ }^{1} \mathrm{H}\right\} \mathrm{NMR}$ & $\begin{array}{c}\text { Alfrey- } \\
\text { Mayo }\end{array}$ & $\begin{array}{c}\text { Monte } \\
\text { Carlo }\end{array}$ \\
\hline \multirow[t]{6}{*}{ AV3 } & 0.25 & AAA & 0.00 & 0.02 & 0.01 & \multirow{6}{*}{ AV6 } & \multirow[t]{6}{*}{0.48} & AAA & 0.16 & 0.13 & 0.08 \\
\hline & & AAV & 0.24 & 0.24 & 0.14 & & & AAV & 0.49 & 0.46 & 0.41 \\
\hline & & VAV & 0.76 & 0.74 & 0.85 & & & VAV & 0.35 & 0.41 & 0.51 \\
\hline & & VVV & 0.54 & 0.50 & 0.62 & & & VVV & 0.21 & 0.17 & 0.11 \\
\hline & & AVV & 0.37 & 0.41 & 0.33 & & & AVV & 0.43 & 0.48 & 0.44 \\
\hline & & AVA & 0.09 & 0.09 & 0.05 & & & AVA & 0.36 & 0.35 & 0.45 \\
\hline \multirow[t]{6}{*}{ AV4 } & 0.33 & AAA & 0.12 & 0.04 & 0.02 & \multirow[t]{6}{*}{ AV7 } & \multirow[t]{6}{*}{0.56} & AAA & 0.28 & 0.21 & 0.20 \\
\hline & & AAV & 0.30 & 0.32 & 0.22 & & & AAV & 0.48 & 0.50 & 0.49 \\
\hline & & VAV & 0.58 & 0.64 & 0.76 & & & VAV & 0.24 & 0.29 & 0.31 \\
\hline & & VVV & 0.36 & 0.37 & 0.46 & & & VVV & 0.14 & 0.09 & 0.05 \\
\hline & & AVV & 0.44 & 0.48 & 0.43 & & & AVV & 0.40 & 0.43 & 0.35 \\
\hline & & AVA & 0.20 & 0.15 & 0.11 & & & AVA & 0.46 & 0.48 & 0.60 \\
\hline \multirow[t]{6}{*}{ AV5 } & 0.41 & AAA & 0.09 & 0.07 & 0.04 & \multirow[t]{6}{*}{ AV8 } & \multirow[t]{6}{*}{0.66} & AAA & 0.39 & 0.36 & 0.45 \\
\hline & & AAV & 0.40 & 0.40 & 0.31 & & & AAV & 0.44 & 0.48 & 0.43 \\
\hline & & VAV & 0.51 & 0.53 & 0.65 & & & VAV & 0.17 & 0.16 & 0.12 \\
\hline & & VVV & 0.31 & 0.26 & 0.25 & & & VVV & 0.02 & 0.04 & 0.02 \\
\hline & & AVV & 0.45 & 0.50 & 0.51 & & & AVV & 0.38 & 0.33 & 0.21 \\
\hline & & AVA & 0.24 & 0.24 & 0.24 & & & AVA & 0.60 & 0.63 & 0.77 \\
\hline
\end{tabular}

${ }^{\text {a }}$ A- and V-centered triad fractions add upto unity.
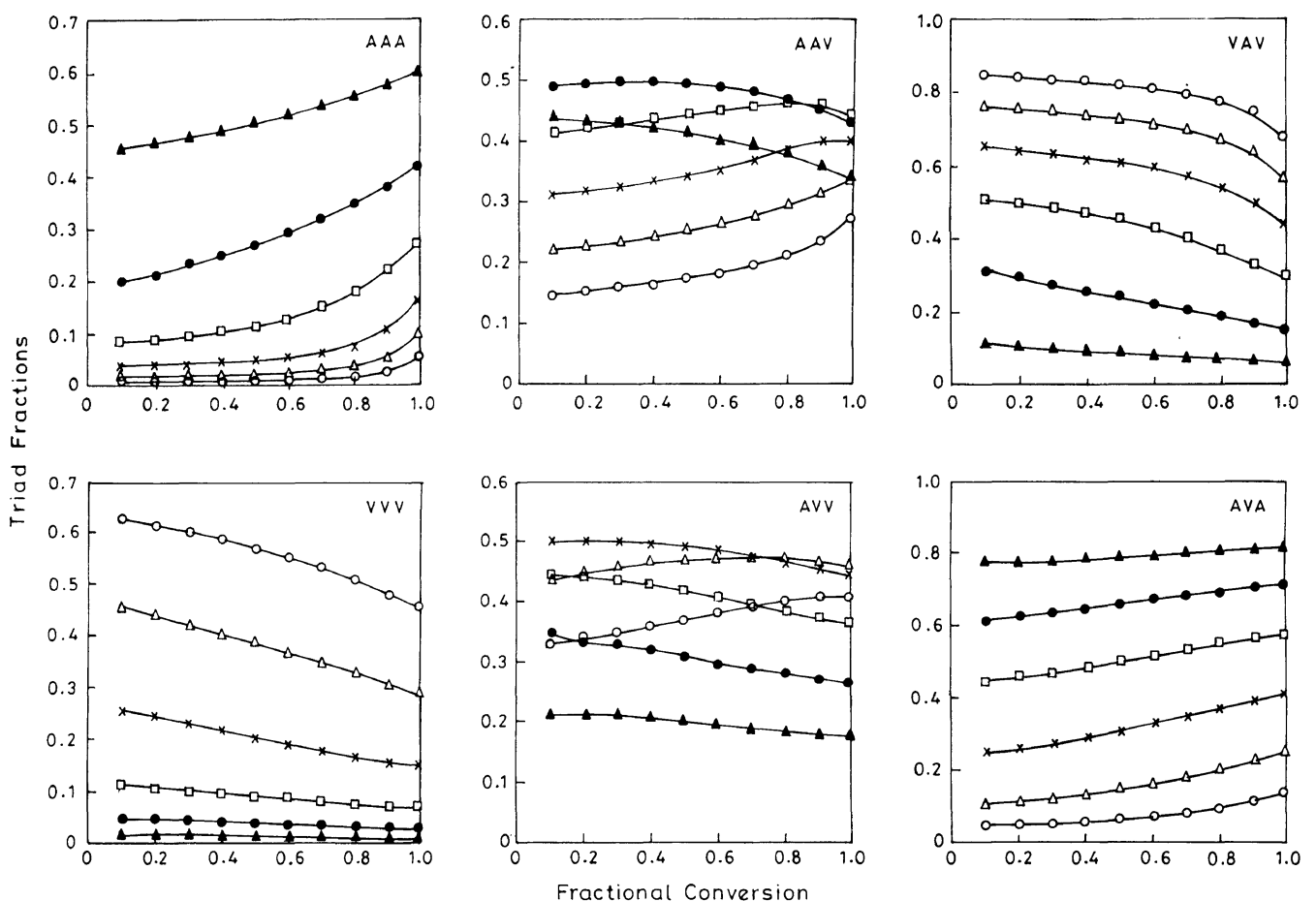

Figure 8. Variation of $\mathrm{A}$ - and $\mathrm{V}$-centered triad fractions plotted as a function of fractional conversion for different feed mole fractions: $f_{\mathrm{A}}=0.3(\bigcirc), f_{\mathrm{A}}=0.4(\triangle), f_{\mathrm{A}}=0.5(\times), f_{\mathrm{A}}=0.6(\square), f_{\mathrm{A}}=0.7(\mathbf{O})$, and $f_{\mathrm{A}}=0.8(\mathbf{\Delta})$.

experimental data (NMR) is 0.94. MC simulation method can also be used to calculate the triad concentration at various fractional conversions. The variation of $\mathrm{A}$ - and $\mathrm{V}$-centered triad concentration as a function of fractional conversion for different feed mole fraction are shown in Figure 8. The trend observed for AAA triad is similar to that of AVA triad. At lower in feed $\left(f_{\mathrm{A}}\right)$, the triad fraction increases only at higher fractional conversion. At higher in feed the triad fraction slowly increases with fractional conversion. The effect is more predominant in AAA triad i.e., AAA triad is formed only at higher fractional conversion due to its lower reactivity ratio. The trend observed in VAV triad is similar to that of VVV triad. At lower in feed, triad fraction decreases sharply at higher fractional conversion. The decrease is more predominant in VAV triad. At higher in feed $\left(f_{\mathrm{A}}>0.6\right)$ the decrease in triad fraction is very nominal almost constant. In AAV and AVV triad at lower in feed $\left(f_{\mathrm{A}}=0.3,0.4\right)$ the triad fraction increases and at higher in feed it decreases with fractional conversion. 


\section{CONCLUSION}

The microstructure of $\mathrm{A} / \mathrm{V}$ copolymer was determined from ${ }^{13} \mathrm{C}\left\{{ }^{1} \mathrm{H}\right\}$ NMR spectroscopy. The copolymerization mechanism, using the carbonyl and quaternary carbon resonances of A- and V-monomeric units was found to follow first order Markov model. The complex proton NMR spectrum of $\mathrm{A} / \mathrm{V}$ copolymers were assigned completely to various compositional and configurational sequences with the help of 2D HSQC and TOCSY experiments. HSQC spectrum shows the presence of inequivalent methylene protons and was confirmed by the geminal couplings observed in the 2D TOCSY spectrum. The sequence distribution of A- and V-centered triads determined from ${ }^{13} \mathrm{C}\left\{{ }^{1} \mathrm{H}\right\}$ NMR spectra of copolymer was in good agreement with triad concentration calculated from statistical model.

Acknowledgment. The authors wish to thank the Council of Scientific Industrial Research (CSIR) for funding the work and Department of Chemistry, Indian Institute of Technology, Delhi for the NMR facility.

\section{REFERENCES}

1. G. Sudesh Kumar and D. C. Neckers, Chem. Rev., 89, 1915 (1989).
2. F. A. Bovey, "High Resolution NMR of Macromolecules," Academic Press, New York, N.Y., 1972.

3. J. C. Randall, "Polymer Sequence Determination (Carbon-13 NMR Method)," Academic Press, New York, N.Y., 1977.

4. P. A. Mirau and F. A. Bovey, Macromolecules, 19, 210 (1986).

5. J. J. Kotyk, P.A.Berger, and E. E. Remson, Macromolecules, 23, 5167 (1990)

6. C. Hijangos and D. Lopez, Macromolecules, 28, 1364 (1995).

7. A. S. Brar, K. Dutta, and G. S. Kapur, Macromolecules, 28, 8735 (1995).

8. L. Dond, D. J. T. Hill, J. H. O'Donnell, and A. K. Whittaker, Macromolecules, 27, 1830 (1994).

9. L. Suzchen and W. Meixiang, Chinese J. Polym. Sci., 15, 108 (1997).

10. L. Hangguan and R. Eli, Polymer, 37, 1933 (1996).

11. H. Menge and S. Horst, Polymer, 34, 4203 (1993).

12. K. C. Lee, M. S. E. Aasser, Vander hoff, and W. John, J. Appl. Polym. Sci., 45, 2221 (1992).

13. A. Altomare, R. Lima, and R. Solaro, Polymer, 32, 1195 (1991).

14. R. Solaro, A. Altomare, and F. Ciardelli, Eur.Polym. J., 26, 649 (1990).

15. A. Altomare, C. Carlini, F. Ciardelli, and R. Solaro, Polym. J., 20, 801 (1988).

16. T. Kelen and F. J. Tüdos, J. Macromol. Sci. Chem. A., 9, 1 (1975).

17. M. J. Box, Technometrics, 12, 219 (1970).

18. M. Dubey, R. Amin Sanyei, A. Penlidis, K. F. O'Driscoll, and P. M. Reilly, J. Polym. Sci. Part A, Polym.Chem., 29, 703 (1991).

19. A. S. Brar, M. Thiyagarajan, and K. Dutta, Polymer, 39, 5507 (1998).

20. A. S. Brar and M. Thiyagarajan, Polymer, 39, 5923 (1998) 